\title{
Evaluation of sensory panels of consumers of specialty coffee beverages using the boosting method in discriminant analysis
}

\section{Avaliação de painéis sensoriais com consumidores de bebidas de cafés especiais utilizando o método boosting na análise discriminante}

\author{
Gilberto Rodrigues Liska ${ }^{1 *}$; Fortunato Silva de Menezes²; Marcelo Ângelo Cirillo; \\ Flávio Meira Borém ${ }^{4}$; Ricardo Miguel Cortez ${ }^{5}$; Diego Egídio Ribeiro ${ }^{6}$
}

\begin{abstract}
Automatic classification methods have been widely used in numerous situations and the boosting method has become known for use of a classification algorithm, which considers a set of training data and, from that set, constructs a classifier with reweighted versions of the training set. Given this characteristic, the aim of this study is to assess a sensory experiment related to acceptance tests with specialty coffees, with reference to both trained and untrained consumer groups. For the consumer group, four sensory characteristics were evaluated, such as aroma, body, sweetness, and final score, attributed to four types of specialty coffees. In order to obtain a classification rule that discriminates trained and untrained tasters, we used the conventional Fisher's Linear Discriminant Analysis (LDA) and discriminant analysis via boosting algorithm (AdaBoost). The criteria used in the comparison of the two approaches were sensitivity, specificity, false positive rate, false negative rate, and accuracy of classification methods. Additionally, to evaluate the performance of the classifiers, the success rates and error rates were obtained by Monte Carlo simulation, considering 100 replicas of a random partition of $70 \%$ for the training set, and the remaining for the test set. It was concluded that the boosting method applied to discriminant analysis yielded a higher sensitivity rate in regard to the trained panel, at a value of $80.63 \%$ and, hence, reduction in the rate of false negatives, at $19.37 \%$. Thus, the boosting method may be used as a means of improving the LDA classifier for discrimination of trained tasters.
\end{abstract}

Key words: Sensory analysis, adaboosting, coffee quality, consumers

\section{Resumo}

Os métodos automáticos de classificação têm sido amplamente utilizados em inúmeras situações, nas quais o método boosting tem se destacado por utilizar um algoritmo de classificação que considera um conjunto de dados de treinamento e, a partir desse conjunto, constrói um classificador com versões reponderadas do conjunto de treinamento. Dada essa característica, esse trabalho tem por objetivo avaliar um experimento sensorial relacionado a testes de aceitação com cafés especiais, tendo como referência grupos de consumidores, treinados e não treinados. Ao grupo de consumidores, foram avaliadas quatro

1 Discente de Doutorado em Estatística e Experimentação Agropecuária, Dept ${ }^{\circ}$ de Ciências Exatas, Universidade Federal de Lavras, UFLA, Lavras, MG, Brasil. E-mail: gilbertoliska@hotmail.com

2 Prof. Associado, Dept ${ }^{\circ}$ de Ciências, UFLA, Lavras, MG, Brasil. E-mail: fmenezes@dex.ufla.br

3 Prof. Adjunto, Dept ${ }^{\circ}$ de Ciências Exatas, UFLA, Lavras, MG, Brasil. E-mail: macufla@dex.ufla.br

4 Prof. Associado, Dept ${ }^{\circ}$ de Engenharia, UFLA, Lavras, MG, Brasil. E-mail: flavioborem@deg.ufla.br

5 Discente de Graduação em Engenharia Agrícola, Dept ${ }^{\circ}$ de Engenharia, UFLA, Lavras, MG, Brasil. E-mail: ricardocortez@ hotmail.com

6 Discente do Doutorado em Engenharia Agrícola, Dept ${ }^{\circ}$ de Engenharia, UFLA, Lavras, MG, Brasil. E-mail: diegoagro@hotmail. com

Author for correspondence 
características sensoriais, tais como aroma, corpo, doçura e nota final, atribuídos a quatro tipos de cafés especiais. Com o propósito de obter uma regra de classificação que discrimine provadores treinados e não treinados, utilizaram-se a análise discriminante de Fisher convencional (LDA) e a análise de discriminante via algoritmo de boosting (Adaboost). Os critérios utilizados na comparação das duas abordagens foram sensibilidade, especificidade, taxa de falsos positivos, taxa de falsos negativos e acurácia dos métodos classificatórios. Adicionalmente, para avaliar o desempenho dos classificadores, as referidas taxas de acerto e erro foram obtidas por simulação Monte Carlo, considerando-se 100 réplicas de uma partição aleatória de $70 \%$ para a amostra de treinamento e o restante para o conjunto de teste. Concluiu-se que o método de boosting aplicado na análise discriminante proporcionou maior taxa de acerto quanto aos provadores treinados, cujo valor foi $80,63 \%$ e, consequentemente, redução na taxa de falsos negativos, cujo valor foi $19,37 \%$. Dessa forma, o método de boosting pode ser utilizado como uma forma de aperfeiçoar o classificador LDA para a discriminação de provadores treinados.

Palavras-chave: Análise sensorial, adaboosting, qualidade de cafés, consumidores

\section{Introduction}

The need for automatic methods of classification arises in various areas of knowledge. The foundation of an automatic classifier consists of using the data in a way that allows creation of a rule to be used to classify other data in the future (BUHLMANN; HOTHORN, 2007). The way this rule is created has a direct effect on aspects like the performance and interpretability of the classifier. Because of that, it is necessary to evaluate the rule through statistical criteria.

In this respect, the boosting methods initially proposed by Schapire (1990) stand out, which arose in the area of pattern recognition. Essentially, they function by sequentially applying a classification algorithm to reweighted versions of the set of training data, giving greater weight to the observations wrongly classified in the previous step. In this context, the most applied boosting algorithm is known as AdaBoost (FREUND; SCHAPIRE, 2012).

In dealing with statistical methods applied to analysis of sensory data, generally, a large part of these methods may be summarized as a set of experimental techniques and multivariate statistics applied for the purpose of verifying the quality or the degree of acceptance of a certain product, without, however, disregarding the characteristics of the individuals in regard to their sensory abilities. By way of illustration, preference maps are cited
(CIABOTTI et al., 2009; MENEZES et al., 2012). In this context, there are no reports of application of the boosting method; nevertheless, the application of this method is viable and relevant because it allows insertion of two distinct groups of consumers; i.e., consumers that have some refined sensory ability(ies) arising from training or knowledge of the product, and totally uninitiated consumers.

In light of this situation, it is plausible to acknowledge that sensory analysis will show few variations if it is applied to a group of trained consumers capable of distinguishing small differences between the samples and the results stemming from the evaluations. Therefore, a sensorial experiment carried out with this group shows greater agreement with the procedures standardized by the Specialty Coffee Association of America - SCAA (2009) since objective evaluations would be more homogeneous for perception of uniformity, sweetness, and defects, among other aspects.

Because of the above, the aim of this paper is to present a comparative study of discriminant analysis, considering incorporation of the boosting method in the discriminant analyses given by Fisher's Linear Discriminant Analysis (FÁVERO et al., 2009) and cross validation following the Monte Carlo procedure.

Both methods were applied to a sensory experiment that considered two distinct groups, 
characterized by the absence and presence of basic training in reference to discrimination of some properties related to the quality of two genotypes of specialty coffee produced in the region of the Serra da Mantiqueira, Minas Gerais, Brazil, at different altitudes and with different manners of processing.

\section{Materials and Methods}

Sample preparation and sensory analysis

In accordance with the consolidated opinion of the Research Ethics Committee, registered in the CAAE: 14959413.1.0000.5148, preparation of the $100 \%$ arabica coffee samples was carried out by removing all defective and toasted grains and respecting the maximum period of 24 hours for taste testing.

The roasting point was determined visually using the color classification system by means of standardized disks (SCAA/AgtronRoast Color Classification System). In regard to beverage preparation, a concentration of $7 \% \mathrm{w} / \mathrm{v}$ was maintained using filtered water ready for consumption, free of any contamination and without added sugar. With these specifications, four types of specialty coffees codified in the samples as A, B, C, and $\mathrm{D}$ were used, as described in Table 1.

Table 1. Description of specialty coffees assessed in sensory analysis with untrained consumers.

\begin{tabular}{cccc}
\hline Type & Genotype & Altitude & Processing \\
\hline A & Bourbon Amarelo & above $1200 \mathrm{~m}$ & Natural \\
B & Acaiá & below $1100 \mathrm{~m}$ & Pulped \\
C & Acaiá & below $1100 \mathrm{~m}$ & Natural \\
D & Bourbon Amarelo & above $1200 \mathrm{~m}$ & Pulped \\
\hline
\end{tabular}

For each type of coffee, the following sensory characteristics were assessed in the acceptance test: aroma, body, hardness, and final score, in four sessions, with the participation of a volunteer group of consumers with basic knowledge in regard to sensory analysis of coffees and another group without basic knowledge. Table 2 provides a list of the tasters, as well as the sensory characteristics assessed by each taster, in which $a_{i j}$ represents the score given by taster $i\left(i=1,2, \ldots, n_{1}, n_{1}+1\right.$, $\left.n_{1}+2, \ldots, n_{2}\right)$, such that $n_{1}+n_{2}=n$, for the sensory characteristic $\times$ coffee $j(j=1,2, \ldots, 10)$ combination.

Table 2. Tabulated representation of the sensory characteristics of the specialty coffees assessed.

\begin{tabular}{|c|c|c|c|c|c|c|c|c|c|c|}
\hline \multirow{2}{*}{ Condition } & \multirow{2}{*}{ Taster } & \multicolumn{4}{|c|}{ Sensory characteristic 1} & \multirow{2}{*}{$\ldots$} & \multicolumn{4}{|c|}{ Sensory characteristic 4} \\
\hline & & $\mathbf{A}$ & B & $\mathbf{C}$ & D & & $\mathbf{A}$ & B & $\mathbf{C}$ & $\mathbf{D}$ \\
\hline \multirow{6}{*}{ Trained } & 1 & $a_{11}$ & $a_{12}$ & $a_{13}$ & $a_{14}$ & $\ldots$ & $a_{113}$ & $a_{114}$ & $a_{115}$ & $a_{116}$ \\
\hline & 2 & $a_{21}$ & $a_{22}$ & $a_{23}$ & $a_{24}$ & $\ldots$ & $a_{213}$ & $a_{214}$ & $a_{215}$ & $a_{216}$ \\
\hline & $\cdot$ & $\cdot$ & $\cdot$ & $\cdot$ & $\cdot$ & & $\cdot$ & $\cdot$ & $\cdot$ & $\cdot$ \\
\hline & $\cdot$ & . & . & . & $\cdot$ & $\cdots$ & . & . & . & . \\
\hline & . & $\cdot$ & $\cdot$ & $\cdot$ & $\cdot$ & & $\cdot$ & $\cdot$ & $\cdot$ & $\cdot$ \\
\hline & $n_{1}$ & $a_{n 11}$ & $a_{n 12}$ & $a_{n 13}$ & $a_{n 14}$ & $\ldots$ & $a_{n 113}$ & $a_{n 114}$ & $a_{n 115}$ & $a_{n 116}$ \\
\hline \multirow{5}{*}{ Untrained } & 1 & $a_{(n 1+1) 1}$ & $a_{(n 1+1) 2}$ & $a_{(n I+1) 3}$ & $a_{(n 1+1) 4}$ & $\cdots$ & $a_{(n 1+1) 13}$ & $a_{(n 1+1) 14}$ & $a_{(n 1+1) 15}$ & $a_{(n I+1) 16}$ \\
\hline & . & - & . & . & . & & . & . & . & \\
\hline & . & . & . & . & . & $\ldots$ & . & . & . & . \\
\hline & . & . & . & . & . & & . & . & . & . \\
\hline & $n_{2}$ & $a_{n 21}$ & $a_{n 22}$ & $a_{n 23}$ & $a_{n 24}$ & $\ldots$ & $a_{n 213}$ & $a_{n 214}$ & $a_{n 215}$ & $a_{n 216}$ \\
\hline
\end{tabular}




\section{AdaBoost algorithm}

Among the numerous algorithms used in the boosting method, the one most found for many applications is the binary classification algorithm, known as AdaBoost (BARTLETT; TRASKIN, 2007; CAO et al., 2010). To utilize this algorithm, a training set is considered, represented by $L=\left(x_{1}, y_{1}\right)$, $\ldots,\left(x_{N}, y_{N}\right)$ where the classes are labeled as $C=\{-1,1\}$ . In this study, $\mathbf{x}_{i}$ represents the multivariate vector of the scores of each taster $i, i=1, \ldots, N$ and $y_{i}$ the classification of the taster (untrained and trained), whose codification is that of set C. Through an iterative process, the AdaBoost algorithm fits a classifier at each iteration with weighted versions of the training set. At the end, the final classifier is obtained, defined by $F(\mathbf{x})=\sum_{1}^{M} c_{m} f_{m}(\mathbf{x})$, with $f_{m}$ being a classifier that returns values $\{-1,1\}$; the $c_{m}$ values are constant, and the corresponding prediction is the sign of $F(\mathbf{x})$, i.e., $\operatorname{sign}(F(\mathbf{x}))$.

Thus, the AdaBoost algorithm attributes greater weight, or weighted values, to the cases that are wrongly classified; the weights are fitted in an adapted manner in each iteration; and the final classifier is a linear combination of the classifiers $f_{m}$. In this study, $f_{m}$ will be the classifier LDA (SKURICHINA; DUIN, 2000).

Given the theoretical basis of the AdaBoost algorithm, computational implementation was given in carrying out the following steps:

1. The initial weights, $w_{i}=1 / N, i=1,2, \ldots, N$, were obtained, with $\mathrm{N}$ being equal to the size of the sample.

2. Given $M$, in which $M$ is the number of iterations of the algorithm, repeat procedure (a) - (c) for $\mathrm{i}=1, . ., \mathrm{M}$.

a) Fit the classifier $f_{m}(\mathbf{x}) \in\{-1,1\}$ using the weights $w_{i}$ in the training data. In this study, the base classifier considered is obtained through Fisher's Linear Discriminant Analysis. b) Calculate $\varepsilon_{m}=E_{w}\left[I_{\left(y \neq f_{m}(\mathbf{x})\right)}\right], c_{m}=0.5 \times \log \left(\left(1-\varepsilon_{m}\right) / \varepsilon_{m}\right)$; in which $E_{w}$ corresponds to the weighted average obtained in the training set, with the weights $w=\left(w_{1}, \ldots, w_{N}\right)$.

c) Make $w_{i} \leftarrow w_{i} \exp \left\{-c_{m} I_{\left(y \neq f_{m}(\mathbf{x})\right)}\right\}, i=1,2, \ldots, N$, and renormalize so that $\sum_{i} w_{i}=1$.

3. The classification of the taster $i$ is given by $\operatorname{sign}(F(\mathbf{x}))=\operatorname{sign}\left(F(\mathbf{x})=\sum_{1}^{M} c_{m} f_{m}(\mathbf{x})\right)$.

In each iteration, the AdaBoost algorithm leads to an increase in $w_{i}$ weights of the observations wrongly classified by a factor that depends on the $\varepsilon_{m}$ errors of the observations of the training set (step 2(c)).

In regard to estimation of the probabilities of classification, two errors were naturally considered, in the following situations:

Error 1, called false negative; the occurrence of this error is seen if the taster is trained; however, the classification rule (discriminant or boosting) classifies him/her as untrained.

Error 2, called false positive; the occurrence of this error is seen if the taster is untrained and the classification rule (discriminant or boosting) classifies him/her as trained.

Thus, the probabilities of occurrence of these errors were represented by $P[$ Error 1$]=P[2 \mid 1]$ and $P[$ Error 2$]=P[1 \mid 2]$, respectively, and the lower these probabilities are, the better the discrimination function will be. That way, it became possible to evaluate the performance of the Fisher linear and boosting classifiers through counting, according to the classification given in Table 3 , in which $n_{k l}$ referred to the number of tasters that belong to the group of origin $k$ and which are classified by the classifier in relation to group $l(k, l,=1,2)$. The situation in which $k=l$ results in the correct number of classifiers, and when $k \neq l$, the number of classifications is incorrect. 
Table 3. Counting of false positives and negatives in reference to classification of tasters in trained and untrained groups.

\begin{tabular}{cccc}
\hline \multirow{2}{*}{ Tasters } & \multicolumn{2}{c}{ Classification } & \multirow{2}{*}{ Total } \\
\cline { 2 - 3 } & $\begin{array}{c}\text { (Group 1) } \\
\text { (Trained) }\end{array}$ & $\begin{array}{c}\text { (Group 2) } \\
\text { (Untrained) }\end{array}$ & \\
\hline Group 1 (Trained) & $n_{11}$ & $n_{12}$ & $n_{1}$ \\
Group 2 (Untrained) & $n_{21}$ & $n_{22}$ & $n_{2}$ \\
\hline
\end{tabular}

Following the frequencies $n_{k l}$, represented according to Table 3, the estimates of the probabilities of occurrence of errors 1 and 2 were obtained according to expressions (1) and (2), respectively, interpreted as false negative and false positive rates.

$$
\begin{aligned}
& \hat{P}[2 \mid 1]=n_{12} / n_{1} \\
& \hat{P}[1 \mid 2]=n_{21} / n_{2}
\end{aligned}
$$

The estimates of probabilities $\hat{P}[1 \mid 1]$ and $\hat{P}[2 \mid 2]$, according to expressions (3) and (4), are interpreted as sensitivity and specificity rates obtained by the classification rule.

$$
\begin{aligned}
& \hat{P}[1 \mid 1]=n_{11} / n_{1} \\
& \hat{P}[2 \mid 2]=n_{22} / n_{2}
\end{aligned}
$$

From expressions (3) and (4), the accuracy or overall success rate $(\mathrm{T})$ of the classifier may be obtained, given by $T=\left(n_{11}+n_{22}\right) / n$, in which $n=n_{1}+n_{2}$.

To evaluate the performance of the classifiers obtained by the two methods, the data set was separated into two parts, one part for training, directed to fitting of the LDA and boosting classifiers, and the test part, directed to validation of the classifiers. The training set will consist of a $70 \%$ partition of the original sample, and the remainder of the partition will make up the testing set, which will be used for calculation of probabilities (1), (2), (3), and (4). The Monte Carlo method was used so that, in 100 simulations, the mean value and the precision of the previously cited probabilities were obtained.

The results were obtained and implementation of the boosting algorithm occurred through creating functions using the R software (DEVELOPMENT CORE TEAM, 2014). The results related to rates (1) - (4) are described in the following section.

\section{Results and Discussion}

In agreement with the proposed methodology, the results described in Table 4 were obtained considering the classifier constructed by Fisher's Linear Discriminant Analysis (LDA), in which it may be noted that the estimated sensitivity rate is approximately $53.85 \%$ and the specificity rate near $58.82 \%$. Given the similarity between these rates, there is statistical evidence to affirm that the classifier generated by Fisher's Discriminant Analysis may be considered as a classifier with reasonable discrimination power. In contrast, if the aforementioned rates were quite different, for example, a sensitivity of $80 \%$ and a specificity of $30 \%$, it would be an indication that the classifier has high power of discrimination in regard to the tasters that are trained, low power of discrimination in regard to the tasters that are not trained, and, consequently, a low rate of false negatives and a high rate of false positives.

In regard to the false positive and false negative rates, the estimated values were $41.18 \%$ and 
$46.15 \%$, respectively. These results indicate that the LDA classifier shows a considerable classification rate of tasters that are not trained, when in fact they are, configuring a false negative, and a considerable classification rate of tasters that are trained, when in fact they are not, configuring a false positive. The overall performance or accuracy of the model was $56.67 \%$, i.e., the discrimination power of the LDA classifier in detecting the tasters that in fact are trained and are not trained is reasonable. Similar success rate also occurred in the study of Barbosa et al. (2014), in which the discriminant analysis method was used for the purpose of discriminating types of processing of specialty coffees considering different stable isotopes (physiological characteristics) in specialty coffee seeds, obtaining an overall success rate of $60 \%$. In the same study, analyzing seed color (red and yellow), the accuracy of the model was $68.9 \%$. In consumer credit analysis, Guimarães and Chaves-Neto (2002) applied the discriminant analysis model and obtained sensitivity and specificity rates of $92.16 \%$ and $92.4 \%$, respectively.

Table 4. Counting of false positives and negatives in reference to classification of tasters in trained and untrained groups using the classifier generated by Fisher's discriminant analysis. The values represent probabilities (\%).

\begin{tabular}{ccc}
\hline \multirow{2}{*}{ Classification observed } & \multicolumn{2}{c}{ Classification by the model } \\
\cline { 2 - 3 } & Group 1 & Group 2 \\
& (Trained) & (Untrained) \\
\hline Group 1 (Trained) & 53.85 & 46.15 \\
Group 2 (Untrained) & 41.17 & 58.82 \\
\hline
\end{tabular}

In regard to cross validation following the Monte Carlo procedure, which consisted of undertaking 100 simulations of partition of the training and test set and for each one of these simulations calculating the success and error rates of the LDA classifier, the prediction power of Fisher's Linear Discriminant Analysis remained consistent in the sense of the values being near those of Table 4 (Table 5). A practical interpretation of Table 5 may be made in the following manner: the LDA classifier showed a Monte Carlo mean value for sensitivity of $64.25 \%$ and Monte Carlo error of $12.07 \%$, which indicates that the classifier showed, in some simulation, a sensitivity rate of $76.32 \%$ for a determined random partition of $70 \%$ of the training set. The accuracy of the LDA classifier showed a Monte Carlo mean value and Monte Carlo error of $60.30 \%$ and $8.23 \%$, respectively. Although the correct and incorrect classification rates are relatively distant from that desired, these results indicate that the LDA classifier for evaluation of trained and untrained tasters may be used in discrimination of the tasters.

In agreement with the results obtained by the LDA method and in an attempt at improving the performance of the classifier, the boosting method was applied as a classifier, and the results are shown in Table 6. 
Table 5. Counting of false positives and negatives in reference to classification of tasters in trained and untrained groups using the classifier generated by Fisher's discriminant analysis and after carrying out the Monte Carlo cross validation procedure. The values represent probabilities (\%).

\begin{tabular}{lcc}
\hline \multicolumn{1}{c}{$\begin{array}{c}\text { Classification } \\
\text { observed }\end{array}$} & \multicolumn{2}{c}{ Classification by the discriminant model } \\
\cline { 2 - 3 } & $\begin{array}{c}\text { Group 1 } \\
\text { (Trained) }\end{array}$ & $\begin{array}{c}\text { Group 2 } \\
\text { (Untrained) }\end{array}$ \\
\hline Group 1 (Trained) & $64.25(12.07)$ & $34.28(12.07)$ \\
Group 2 (Untrained) & $42.21(13.51)$ & $57.79(13.51)$ \\
\hline
\end{tabular}

Table 6. Counting of false positives and negatives in reference to classification of tasters in trained and untrained groups using the classifier generated by the boosting method. The values represent probabilities (\%).

\begin{tabular}{ccc}
\hline \multirow{2}{*}{ Classification observed } & \multicolumn{2}{c}{ Classification by the model } \\
\cline { 2 - 3 } & Group 1 & Group 2 \\
& (Trained) & (Untrained) \\
\hline Group 1 (Trained) & 85.71 & 14.29 \\
Group 2 (Untrained) & 68.75 & 31.25 \\
\hline
\end{tabular}

Through use of the boosting method applied to Fisher's discriminant analysis, the results shown in Table 6 illustrate that the sensitivity of the classifier is at $85.71 \%$, with specificity of $31.25 \%$. Thus, it may be perceived that the boosting method in fact shows high discriminating power of the tasters in relation to the training in this case study involving sensory analysis of specialty coffees. In the case of the false negative rate, it may be seen that the estimate was less than the previous method (Tables 4 and 5), resulting in a rate of $14.29 \%$. This fact allows us to affirm that the LDA classifier constructed through the boosting algorithm led to greater discrimination capacity for the tasters that in fact are trained and, consequently, a reduction in the incorrect discrimination of such tasters. In the same way, the discriminatory capacity or accuracy of the LDA model through boosting was $56.67 \%$, which indicates that this classifier showed the same accuracy as the LDA; nevertheless, it provided for a greater success rate for the trained tasters.

In regard to cross validation following the Monte Carlo procedure, the prediction power of Fisher's Linear Discriminant Analysis was refined when the boosting method was applied, in the sense of the values being near those of Table 6 (Table 7). In an analogous way to Table 5, a practical interpretation of Table 7 may be made in the following way: the LDA classifier through boosting showed a Monte Carlo mean value

for sensitivity of $80.63 \%$ and Monte Carlo error of $19.60 \%$, which indicates that the classifier showed, in some simulation, a sensitivity rate near $100 \%$ for a determined random partition of $70 \%$ of the training set. The accuracy of the LDA classifier through boosting showed a Monte Carlo mean value and Monte Carlo error of $50.47 \%$ and $8.83 \%$, respectively. 
Table 7. Counting of false positives and negatives in reference to classification of tasters in trained and untrained groups using the classifier generated by the boosting method and after carrying out the Monte Carlo cross validation procedure. The values represent probabilities (\%).

\begin{tabular}{ccc}
\hline \multirow{2}{*}{ Classification observed } & \multicolumn{2}{c}{ Classification by the model } \\
\cline { 2 - 3 } & Group 1 & Group 2 \\
& (Trained) & (Untrained) \\
\hline Group 1 (Trained) & $80.63(19.60)$ & $19.37(19.10)$ \\
Group 2 (Untrained) & $71.45(24.37)$ & $28.55(24.37)$ \\
\hline
\end{tabular}

A high percentage of correct classification (90.1\%) was also found in the study of Estévez et al. (2004), who studied the differences between two groups of patients dependent on opium and a control group, considering biochemical and hematological variables of nutritional importance in the blood samples of patients. The literature lacks studies that involve the utility of the boosting method in LDA; nevertheless, Cao et al. (2010) compared a boosting algorithm with another classifier well-known in machine learning, the support vector machines, and concluded that the boosting algorithm showed superior accuracy in classification of structural classes of proteins. Boosting was also successfully applied in the studies of Cai et al. (2006), Shafik and Tutz (2009), and Buhlmann and Hothorn (2007).

\section{Conclusions}

The Discriminant Analysis method may be used to obtain a classification rule of coffee tasters, showing a reasonable success rate.

The boosting method was successfully applied in LDA and provided for a greater sensitivity rate and lower false negative rate in relation to conventional LDA analysis; i.e., the boosting method increased the capacity of the LDA classifier in correctly classifying tasters that are trained.

\section{Acknowledgments}

To the CAPES and to the CNPq for financial support.

\section{References}

BARBOSA, J.; BOREM, F.; ALVES, H.; CIRILlO, M.; SARTON, M.; DUCATTI, C. Discrimination of production environments of specialty coffees by means of stable isotopes and discriminant model. Journal of Agricultural Science, Toronto, v. 6, n. 5, p. 55-64, 2014.

BARTLETT, P.; TRASKIN, M. AdaBoost is consistent. Journal of Machine Learning Research, Massachusetts, v. 8, n. 1, p. 2347-2368, 2007.

BUHLMANN, P.; HOTHORN, T. Boosting algorithms: regularization, prediction and model fitting. Statistical Science, New York, v. 22, n. 4, p. 477-505, 2007.

CAI, Y. D.; FENG, K. Y.; LU, W. C.; CHOU, K. C. Using logit boost classifier to predict protein structural classes. Journal of Theoretical Biology, London, v. 238, n. 1, p. 172-176, 2006.

CAO, D. S.; XU, Q. S.; LIANG, Y. Z.; ZHANG, L. X.; LI, H. D. The boosting: a new idea of building models. Chemometrics and Intelligent Laboratory Systems, Amsterdam, v. 100, n. 1, p. 1-11, 2010.

CIABOTTI, S.; BARCELOS, M. F. P.; CIRILLO, M. A.; PINHEIRO, A. C. M. Propriedades tecnológicas e sensoriais de produto similar ao tofu obtido pela adição de soro de leite ao extrato de soja. Ciência e Tecnologia de Alimentos, Campinas, v. 29, n. 2, p. 346-353, 2009.

ESTÉVEZ, J.F.D.F.;ESTÉVEZ,F.D.F.; CALZADILLA, C. H.; RODRÍGUES, E. M. R.; ROMERO, C. D.; SERRA MAJEM, L. Application of linear discriminant analysis to the biochemical and haematological differentiation of opiate addicts from healthy subjects: a case-control study. European Journal of Clinical Nutrition, London, v. 58, n. 3, p. 449-455, 2004.

FÁVERO, L. P.; BELFIORE, P.; SILVA, F. L.; CHAN, B. L. Análise de dados: modelagem multivariada para tomada de decisões. Rio de Janeiro: Elsevier, 2009. 646 p. 
FREUND, Y.; SCHAPIRE, R. E. Boosting: foundations and algorithms. Massachusetts: Institute of Technology, 2012. $526 \mathrm{p}$.

GUIMARÃES, I. A.; CHAVES-NETO, A. Reconhecimento de padrões: metodologias estatísticas em crédito ao consumidor. RAE-Eletrônica, Bela Vista, v. 1, n. 2, p. 1-14, 2002.

MENEZES, C. C.; BORGES, S.; CARNEIRO, J. D.; CIRILLO, M. A.; OLIVEIRA, L. F. Optimization of sweet guava (Psidium guajava, L) using the acceptance test, response surface methodology and preference map. Boletim do Centro de Pesquisa e Processamento de Alimentos, Curitiba, v. 30, n. 1, p. 1-10, 2012.

R DEVELOPMENT CORE TEAM. R: A language and environment for statistical computing. $\mathrm{R}$ Foundation for Statistical Computing. Vienna: Vienna University of Economics and Business, 2015. Available at: < http:// www.R-project.org/>. Accessed at: 20 feb. 2015.
SCHAPIRE, R. E. The strength of weak learnability. Machine Learning, Massachusetts, v. 5, n. 1, p. 197-227, 1990.

SHAFIK, N.; TUTZ, G. Boosting nonlinear additive autoregressive time series. Computational Statistics \& Data Analysis, Cambridge, v. 53, n. 7, p. 2453-2464, 2009.

SKURICHINA, M.; DUIN, R. P. W. Boosting in linear discriminant analysis. Multiple Classifier Systems: Lecture Notes in Computer Science, Cagliari, v. 1857, n. 1, p. 190-199, 2000.

SPECIALITY COFFE ASSOCIATION OF AMERICASCAA Protocols - cupping specialty coffee. California: Long Beach, SCAA, 2009. 7 p. 
